\title{
A new 2D dibutyltin coordination polymer with 3,5-dinitrosalicylate and 4,4'-bipyridine ligands
}

https://doi.org/10.1515/mgmc-2020-0024

Received August 21, 2020; accepted November 05, 2020.

Abstract: A new 2D dibutyltin coordination polymer with 3,5-dinitrosalicylate and 4,4'-bipyridine ligands, $\left[\left\{\mathrm{Bu}_{2} \mathrm{Sn}\left(3,5-\left(\mathrm{NO}_{2}\right)_{2}-2-\mathrm{OC}_{6} \mathrm{H}_{2} \mathrm{COO}\right)\right\}_{2}\left(4,4^{\prime}-\mathrm{bpy}\right)\right]_{\mathrm{n}} \quad$ (1), has been synthesized and characterized both spectroscopically (IR, ${ }^{1} \mathrm{H},{ }^{13} \mathrm{C}$, and ${ }^{119} \mathrm{Sn}$ NMR) and a single-crystal X-ray diffraction analysis. The coordination geometry of tin atom in $\mathbf{1}$ is a distorted octahedron. 3,5-Dinitrosalicylate as doubly charged anion ligand adopts chelating-bridging mode to coordinate to tin atoms, and 4,4'-bipyridine further bridges the tin atoms to form a 2D herringbone-like network structure containing the 34-membered hexanuclear macrocycles.

Keywords: organotin complex, 3,5-dinitrosalicylic acid, 4,4'-bipyridine, crystal structure

Organotin carboxylates (such as $\mathrm{R}^{\prime} \mathrm{COOSnR}_{3}$ and $\left(\mathrm{R}^{\prime} \mathrm{COO}\right)_{2} \mathrm{SnR}_{2}$ ) are a kind of important organotin compounds, and their structures and biological activities have been receiving considerable attention (Banti et al., 2019; Chandrasekhar et al., 2013; Chen et al., 2020; Khan et al., 2020; Tian et al., 2019). Salicylic acid $\left(\mathrm{H}_{2} \mathrm{~L}\right)$ has antiseptic and antifungal properties and is widely used in organic synthesis. Structurally, salicylic acid or substituted salicylic acid has two functional groups $(\mathrm{COOH}$ and $\mathrm{OH})$, and can act as a monoanionic $\left(\mathrm{HL}^{-}\right)$or dianionic ( $\mathrm{L}^{2-}$ ) ligand to coordinate to tin atom (Figure 1). The syntheses, structures, and biological activities of some organotin salicylates or substituted salicylates have been reported by several research groups (Basu Baul et al., 2006, 2018, 2019; Kundu et al., 2014; Liu et al., 2019;

*Corresponding author: Laijin Tian, Key Laboratory of Natural Products and Pharmaceutical Intermediates, Qufu Normal University, Qufu 273165, China; e-mail: laijintian@163.com

Ruili Wang, Jiawei Zhang and Qingtao Liu, Key Laboratory of Natural Products and Pharmaceutical Intermediates, Qufu Normal University, Qufu 273165, China
Zhang et al., 2016). However, only a few organotin salicylates with six-membered chelate ring formed by the oxygen atoms of both phenolate and carboxylate coordination to tin have been reported (Figure 1b) (Basu Baul et al., 2018, 2019; Kundu et al., 2014; Prabusankar and Murugavel, 2004; Tian et al., 2011). In organotin chemistry, the combination of a carboxylate ligand and $\mathrm{N}$-donor ligand, such as 4,4'-bipyridine, is widely used for constructing the organotin coordination polymers. Basu Baul's group used heteroditopic pyridylsalicylate ligands, such as 5-[(E)-2-(3 or 4-pyridyl)-1diazenyl] salicylic acid, to construct the 1D and 2D organotin coordination polymers (Basu Baul et al., 2018, 2019). Chandrasekhar and Thirumoorthi synthesized the $1 \mathrm{D}$ triphenyltin coordination polymer by the reaction of 1,1'-ferrocenedicarboxylic acid with bis(triphenyltin) oxide in the presence of 4,4'-bipyridine (Chandrasekhar and Thirumoorthi, 2010). Kundu's group prepared a 1D dibutyltin coordination polymer by the combination of 3,5-dinitrosalicylic acid and 6,6-bis(4-pyridinyloxy) cyclophosphazene ligands (Kundu et al., 2014). In this short communication, we report a new 2D dibutyltin coordination polymer (1) with 3,5-dinitrosalicylate and 4,4'-bipyridine ligands (see Scheme 1).

Coordination polymer $\mathbf{1}$ is obtained from the reaction of dibutyltin oxide, 3,5-dinitrosalicylic acid and 4,4-bipyridine in the molar ratio 1:1:0.5 with a yield of $67 \%$ (Scheme 1). At room temperature, 1 is insoluble in chloroform and acetone, but soluble in DMSO. The NMR spectra in DMSO- $d_{6}$ show the expected resonance absorption of ${ }^{1} \mathrm{H}$ and ${ }^{13} \mathrm{C}$ nuclei (see ESI). The position of the proton signals of 4,4'-bipyridine in $\mathbf{1}$ is identical to that of the free 4,4'-bipyridine ligand (see Figures S2 and S3 in Supplementary Material), indicating that 4,4'-bipyridine in $\mathbf{1}$ is released in DMSO- $d_{6}$ solution. The ${ }^{119} \mathrm{Sn}$ chemical shifts primarily depend on the coordination number and the type of the donor atoms bonded to tin atom (Holecek et al., 1983, 1986). Holecek and coworkers established for butyltin compounds that four-coordinate compounds have $\delta\left({ }^{119} \mathrm{Sn}\right)$ values in solution ranging from +200 to $-60 \mathrm{ppm}$, five-coordinate compounds from -90 to $-190 \mathrm{ppm}$ and 
six-coordinate compounds from -210 to $-400 \mathrm{ppm}$ (Holecek et al., 1986). Compound 1 displays a single ${ }^{119} \mathrm{Sn}$ resonance at $-262 \mathrm{ppm}$, suggesting that the tin atom in 1 is six-coordinated in the coordination solvent DMSO- $d_{6}$ and the six coordinated atoms come from two carbons of organic groups, a phenolic $\mathrm{O}$ and a carboxylic $\mathrm{O}$ of salicylate ligand, and two 0 atoms of two DMSO- $d_{6}$.

The $v(\mathrm{C}=\mathrm{N})$ band in $\mathbf{1}$ appears at $1606 \mathrm{~cm}^{-1}$, which is blue-shifted compared with the free 4,4'-bipyridine ligand $\left(1589 \mathrm{~cm}^{-1}\right)$, confirming the coordination of $\mathrm{N}$ atom to tin atom (Kondo et al., 1997; Ma et al., 2004; Shi et al., 2010). The difference between $v_{\text {as }}(\mathrm{COO})\left(1634 \mathrm{~cm}^{-1}\right)$ and $v_{\mathrm{s}}(\mathrm{COO})$ $\left(1447 \mathrm{~cm}^{-1}\right)\left(\Delta v=187 \mathrm{~cm}^{-1}\right)$ indicates the bidentate bridging coordination of the carboxylate group in the ligand (Deacon and Phillips, 1980; Tian et al., 2020).

In the crystalline state, as shown in Figures 2 and 3, compound $\mathbf{1}$ has a 2D herringbone-like network structure (Zang et al., 2006). The coordination geometry of tin atom is a distorted octahedron, and the six coordinated atoms come from two carbons [C(1) and $\mathrm{C}(5)]$ of butyl groups, one nitrogen $\mathrm{N}(1)$ of 4,4'-bipyridine and three oxygen atoms of two 3,5-dinitrosalicylate ligands, a phenolic $\mathrm{O}(1)$,<smiles>O=C(O[Sn])c1ccccc1O</smiles>

(a)<smiles>O=C1O[Sn]Oc2ccccc21</smiles>

(b)
Figure 1: Coordination modes of salicylate ligand with tin atom in (a) monoanionic and (b) dianionic forms. and a carboxylic $\mathrm{O}(2)$ and a carbonyl $\mathrm{O}(3 \mathrm{~A})$ (symmetry code A: $-x+1 / 2, y-1 / 2,-z+3 / 2$ ) (Figure 2). The three bond angles around tin atom in trans-position, $\mathrm{C}(1)-\mathrm{Sn}(1)-\mathrm{C}(5)$, $\mathrm{O}(1)-\mathrm{Sn}(1)-\mathrm{O}(3 \mathrm{~A})$, and $\mathrm{O}(2)-\mathrm{Sn}(1)-\mathrm{N}(1)$, are 160.92(15), $159.57(8)$ and $164.60(8)^{\circ}$, respectively (Table 1 ).

Every dianionic 3,5-dinitrosalicylate ligand is bound to the tin atom in a chelating-bridging mode. The phenolate $\mathrm{O}(1)$ and carboxylate $\mathrm{O}(2)$ atoms coordinate to tin atom to produce a six-membered chelate ring with a $\mathrm{O}(1)-\mathrm{Sn}(1)-\mathrm{O}(2)$ angle of $81.79(7)^{\circ}$. The carbonyl $\mathrm{O}(3)$ atom bridges the other tin atom to form a $1 \mathrm{D}$ infinite chain with a $\operatorname{Sn}(1)-O(3 A)$ bond of 2.353(2) $\AA$, which is similar to that found in $\mathrm{Bu}_{2} \mathrm{Sn}\left(3,5-\left(\mathrm{NO}_{2}\right)_{2}-2-\mathrm{OC}_{6} \mathrm{H}_{2} \mathrm{COO}\right)$ $\left(\mathrm{CH}_{3} \mathrm{OH}\right)$ (Tian et al., 2011). In the chain, the neighboring Sn ..Sn distance is 5.682(4) $\AA$, and the $\mathrm{Sn} \cdots \mathrm{Sn} \cdot$. Sn angle is $104.91(3)^{\circ}$. The C-O distances (1.245(3) and 1.259(3) Å) in carboxylate moiety do not differ significantly, which is the characteristic of the bridging coordination of carboxylic group (Chandrasekhar et al., 2002; Ma et al., 2006). The $1 \mathrm{D}$ chains are connected by the coordination of $\mathrm{N}(1)$ atom in 4,4-bipyridine to tin atom to give rise to a 2D herringbone structural motif with a $\mathrm{Sn}(1)-\mathrm{N}(1)$ bond of 2.548(3) $\AA$. The 2D structure contains large 34-membered six-nuclear macrocycles with the maximum Sn ... Sn distance of 19.715(4) A. In the literatures (CSD version 5.41, Aug 2020), there is only one example of 2D organotin salicylate complexes, $\left[\mathrm{Bu}_{2} \mathrm{Sn}(5-(4-\mathrm{PyN}=\mathrm{N})-2-\right.$ $\mathrm{OC}_{6} \mathrm{H}_{3} \mathrm{COO}$ ) $]_{\mathrm{n}}$ (Basu Baul et al., 2018). In the case, the tin atoms are bridged by a carboxylate $\mathrm{O}$ atom (i.e. $\mathrm{Sn}-\mathrm{O} \rightarrow \mathrm{Sn}$ ) to form a 4-membered $\mathrm{Sn}_{2} \mathrm{O}_{2}$ ring. Thus, complex 1 is the first example of $2 \mathrm{D}$ organotin salicylate complex containing the carboxylate bridging coordination (i.e. $\mathrm{Sn}-\mathrm{O}-\mathrm{C}=\mathrm{O} \rightarrow \mathrm{Sn}$ ).<smiles>CCCCO[P+](=O)[O-]</smiles>

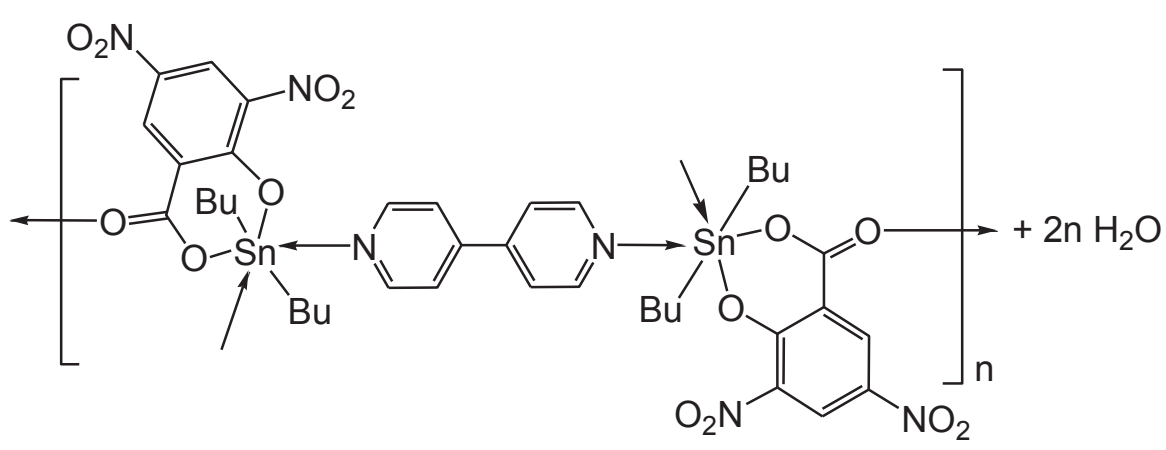

Scheme 1: Synthesis of compound 1. 


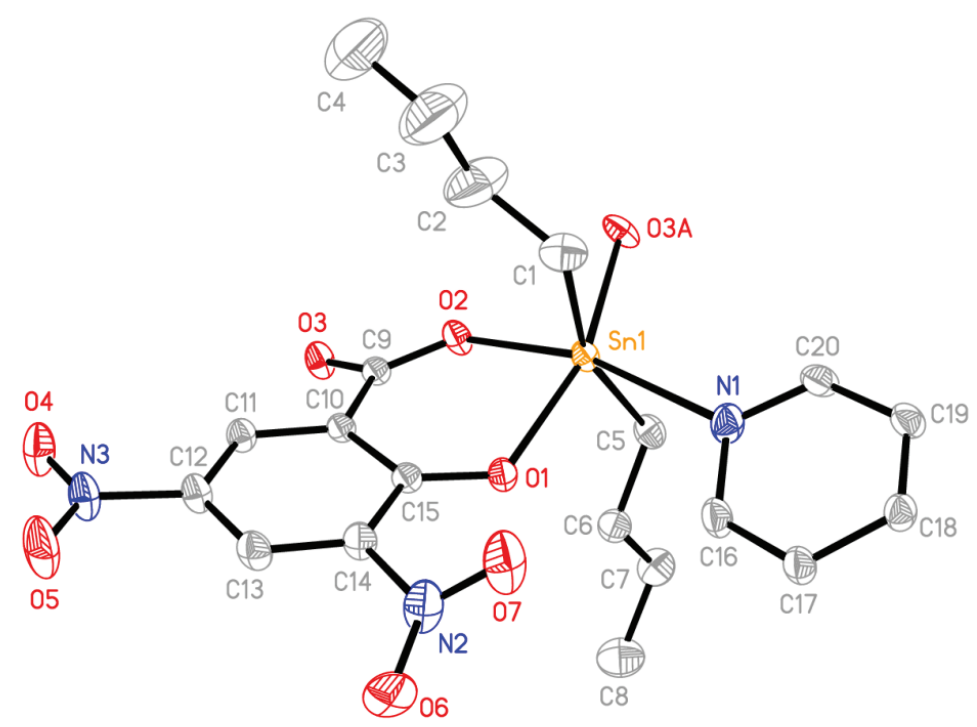

Figure 2: Perspective view of the asymmetric unit of compound 1. Ellipsoids are drawn at the $30 \%$ probability level. Hydrogen atoms are omitted for clarity. Symmetry code A: $-x+1 / 2, y-1 / 2,-z+3 / 2$.

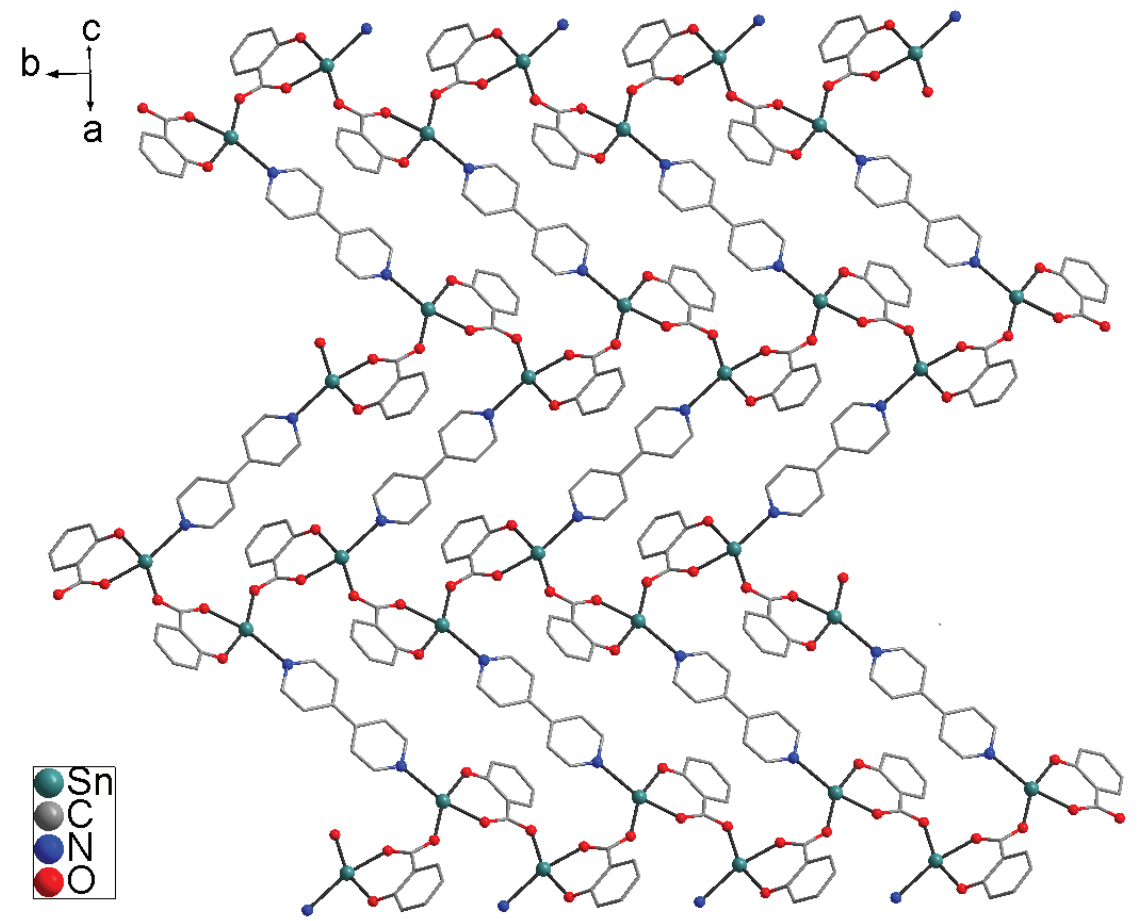

Figure 3: $2 \mathrm{D}$ herringbone structure of 1 containing 34-membered hexa-nuclear macrocyclic rings. The nitro and butyl groups are omitted for clearity.

\section{Experimental}

All of the chemicals were obtained from Sinopharm Chemical Reagent Co., Ltd and Shanghai Darui Fine-chemical Co. Ltd (China). In the experiment, the measuring instruments used are as follows: Perkin
Elmer 2400 Series II elemental analyzer (C, H, and N) (Perkin Elmer, Waltham, USA), Nicolet Nexus 470 FT-IR spectrophotometer ( $\mathrm{KBr}$ pellets) (Thermo Nicolet Corporation, Madison, USA), Bruker Avance III HD $500 \mathrm{MHz}$ NMR spectrometer $\left({ }^{1} \mathrm{H},{ }^{13} \mathrm{C}\right.$, and ${ }^{119} \mathrm{Sn}$ ) (Bruker Corporation, Switzerland). 
Table 1: Selected bond lengths $(\AA)$ and angles $\left(^{\circ}\right)$ for 1.

\begin{tabular}{|c|c|}
\hline $\operatorname{Sn}(1)-C(1)$ & $2.101(3)$ \\
\hline $\operatorname{Sn}(1)-C(5)$ & $2.118(3)$ \\
\hline $\operatorname{Sn}(1)-N(1)$ & $2.548(3)$ \\
\hline $\operatorname{Sn}(1)-0(1)$ & $2.1376(19)$ \\
\hline $\operatorname{Sn}(1)-0(2)$ & $2.1428(19)$ \\
\hline $\operatorname{Sn}(1)-0(3 A)$ & $2.353(2)$ \\
\hline$C(1)-S n(1)-C(5)$ & $160.92(15)$ \\
\hline$C(1)-S n(1)-O(1)$ & $95.87(13)$ \\
\hline$C(5)-S n(1)-O(1)$ & $98.38(11)$ \\
\hline$C(1)-S n(1)-O(2)$ & $100.43(13)$ \\
\hline$C(5)-S n(1)-O(2)$ & $94.13(12)$ \\
\hline$O(1)-S n(1)-O(2)$ & $81.79(7)$ \\
\hline$C(1)-S n(1)-O(3 A)$ & $89.36(13)$ \\
\hline$C(5)-S n(1)-O(3 A)$ & $81.67(12)$ \\
\hline$O(1)-S n(1)-O(3 A)$ & $159.57(8)$ \\
\hline$O(2)-S n(1)-O(3 A)$ & $77.84(8)$ \\
\hline$C(1)-S n(1)-N(1)$ & $83.52(13)$ \\
\hline$C(5)-S n(1)-N(1)$ & $85.69(12)$ \\
\hline$O(1)-S n(1)-N(1)$ & $83.00(8)$ \\
\hline $\mathrm{O}(2)-\mathrm{Sn}(1)-\mathrm{N}(1)$ & $164.60(8)$ \\
\hline $\mathrm{O}(3 \mathrm{~A})-\mathrm{Sn}(1)-\mathrm{N}(1)$ & $117.27(9)$ \\
\hline
\end{tabular}

Symmetry code $A:-x+1 / 2, y-1 / 2,-z+3 / 2$

Table 2: Crystallographic and refinement data for 1.

\begin{tabular}{ll}
\hline Empirical formula & $\mathrm{C}_{20} \mathrm{H}_{24} \mathrm{~N}_{3} \mathrm{O}_{7} \mathrm{Sn}$ \\
Formula weight & 537.11 \\
Crystal system & monoclinic \\
Space group & $P 2_{1} / \mathrm{n}$ \\
$a / \AA$ & $13.2883(7)$ \\
$b / \AA$ & $9.0104(5)$ \\
$c / \AA$ & $18.6482(11)$ \\
$\beta /\left(^{\circ}\right)$ & $94.4050(10)$ \\
Volume $/ \AA^{3}$ & $2226.2(2)$ \\
$Z$ & 4 \\
$D_{\mathrm{c}} /\left(\mathrm{g} \cdot \mathrm{cm}^{-3}\right)$ & 1.603 \\
$\mu / \mathrm{mm} \mathrm{m}^{-1}$ & 1.193 \\
$F(000)$ & 1084 \\
$\theta$ range $/\left({ }^{\circ}\right)$ & $1.8-26.0$ \\
Crystal size $/ \mathrm{mm}$ & $0.50 \times 0.42 \times 0.40$ \\
Tot. reflections & 13832 \\
Uniq. reflections, $R_{\text {int }}$ & $4372,0.022$ \\
$\mathrm{GOF}$ on $F^{2}$ & 1.023 \\
$R_{1}$ indices $[/>2 \sigma(I)]$ & 0.030 \\
$w R_{2}$ indices $($ all data) & 0.086 \\
$\Delta \rho_{\min }, \Delta \rho_{\text {max }} /\left(\mathrm{e} \cdot \AA^{-3}\right)$ & $-0.456,0.527$ \\
$\mathrm{CCDC}$ No. & 2022568 \\
\hline
\end{tabular}

\section{Synthesis of 1}

3,5-Dinitrosalicylic acid (0.228 g, $1.0 \mathrm{mmol}), \mathrm{Bu}_{2} \mathrm{SnO}$ $(0.249 \mathrm{~g}, 1.0 \mathrm{mmol})$, and $50 \mathrm{~mL}$ anhydrous methanol were added to a $100 \mathrm{~mL}$ flask. Under continuous stirring, the reaction mixture was refluxed for $3 \mathrm{~h}$, and turned into a yellow clear solution. A methanol solution $(15 \mathrm{~mL})$ of 4,4'-bipyridine ( $0.078 \mathrm{~g}, 0.5 \mathrm{mmol}$ ) was slowly added. The solution was refluxed for another hour and filtered when hot. The filtrate was evaporated slowly to obtain yellow block crystals. The yield of 1 was $0.362 \mathrm{~g}$ (67\%), and m.p. $>200^{\circ} \mathrm{C}$. Anal. Found: C, 44.62; H, 4.36; N, 7.78. Calcd for $\mathrm{C}_{40} \mathrm{H}_{48} \mathrm{~N}_{6} \mathrm{O}_{14} \mathrm{Sn}_{2}:$ C, 44.72; H, 4.50; N, 7.82\%. IR ( $\mathrm{KBr}$ pellets, $\left.\mathrm{cm}^{-1}\right)$ : $3091(\mathrm{w}), 2957(\mathrm{w}), 2929(\mathrm{w}), 2859(\mathrm{w}), 1634$ [s, v $\left.v_{\mathrm{as}}(\mathrm{COO})\right], 1606$ [s, v(C=N)], $1568(\mathrm{~m}), 1532(\mathrm{~s}), 1489(\mathrm{~m})$, 1447 [s, v $(\mathrm{COO})], 1412(\mathrm{~m}), 1350$ (s), 1325 (s), 1289 (s), 1169 (m), $1081(\mathrm{~m}), 809(\mathrm{~s}), 706(\mathrm{w}), 627(\mathrm{w}) .{ }^{1} \mathrm{H}$ NMR (DMSO- $d_{6}$, $\delta$ ): $0.78\left(\mathrm{t}, J=7.2 \mathrm{~Hz}, 12 \mathrm{H}, \mathrm{CH}_{3}\right), 1.23(\mathrm{sex}, J=7.2 \mathrm{~Hz}, 8 \mathrm{H}$, $\left.\mathrm{CH}_{2}\right), 1.35-1.38\left(\mathrm{~m}, 8 \mathrm{H}, \mathrm{CH}_{2}\right), 1.43-1.48\left(\mathrm{~m}, 8 \mathrm{H}, \mathrm{CH}_{2}\right), 7.83$ (d, $J=6.0 \mathrm{~Hz}, 4 \mathrm{H}, \mathrm{Py}-\mathrm{H}-3), 8.61$ (d, $J=0.4 \mathrm{~Hz}, 2 \mathrm{H}$, Sal-H6), $8.72(\mathrm{~d}, J=6.0 \mathrm{~Hz}, 4 \mathrm{H}, \mathrm{Py}-\mathrm{H}-2), 8.82(\mathrm{~d}, J=0.4 \mathrm{~Hz}, 2 \mathrm{H}$, Sal-H-4). ${ }^{13} \mathrm{C}$ NMR (DMSO- $d_{6}, \delta$ ): 165.36 (COO), 163.81 (Sal-C-2), 151.00 (Py-C-2), 144.82 (Py-C-4), 143.35 (Sal-C-5), 134.00 (Sal-C-3), 131.47 (Sal-C-6), 124.14 (Sal-C-4), 123.09 (Py-C-3), 121.72 (Sal-C-1), $30.60\left(\mathrm{CH}_{2}\right), 27.19\left(\mathrm{CH}_{2}\right), 25.97$ $\left(\mathrm{CH}_{2}\right), 13.93\left(\mathrm{CH}_{3}\right) .{ }^{119} \mathrm{Sn}$ NMR (DMSO-d 6 , $\delta$ ): -261.6 .

\section{X-ray crystallography}

A yellow crystal suitable for X-ray diffraction was obtained from the methanol solution. The intensity data were collected at 295(2) $K$ on a Bruker Smart Apex Diffractometer with graphite monochromated Mo-K $\alpha$ radiation $(0.71073 \AA)$. The structure was solved by direct methods using SHELXS-97 (Sheldrick, 2008) and refined by full-matrix least squares on $F^{2}$ using the SHELXL2014 program (Sheldrick, 2015). All non-hydrogen atoms were refined anisotropically, and hydrogen atoms were placed in calculated positions using the riding model. The disordered atoms (nitro group and pyridine ring) were split over two sites with a total occupancy of 1 . In the refinement, the PART, DFIX, SIMU, and DELU instructions were used. Crystallographic data, refinement parameters, and the CCDC number are summarized in Table 2.

\section{References}

Banti C.N., Hadjikakou S.K., Sismanoglu T., Hadjiliadis N., Anti-proliferative and antitumor activity of organotin(IV) compounds. An overview of the last decade and future perspectives.J.Inorg. Biochem., 2019,194,114-152, DOI:10.1016/ j.jinorgbio.2019.02.003.

Basu Baul T.S., Rynjah W., Rivarola E., Lycka A., Holcapek M., Jirasko R., et al., Synthesis and characterization of bis[dicarboxylatotetr aorganodistannoxane] units involving 5-[(E)-2-(aryl)-1-diazenyl]2-hydroxybenzoic acids: An investigation of structures by X-ray 
diffraction, NMR, electrospray ionization MS and assessment of in vitro cytotoxicity. J. Organomet. Chem., 2006, 691, 4850-4862, DOI: 10.1016/j.jorganchem.2006.08.005.

Basu Baul T.S., Chaurasiya A., Duthie A., Vasquez-Rios M.G., Höpfl H., Solvent and intermolecular nitrogen coordination dictated formation of self-assembled organostannanemacrocycles based on monomers and coordination polymers with unsymmetrical 5-[(E)-2-(4-pyridyl)-1-diazenyl]-2-hydroxybenzoate ligand: Structural topologies and dimensionality. J. Organomet. Chem., 2018, 872, 87-101, DOI: 10.1016/j. jorganchem.2018.07.028.

Basu Baul T.S., Chaurasiya A., Duthie A., Montes-Tolentino P., Höpfl H., Coordination-driven self-assembly of macrocycles and $1 D$ or $2 D$ coordination polymers using heteroditopic pyridyl-carboxylate ligands: the case study of 5-[(E)-2-(3-pyridyl)-1-diazenyl]-2hydroxybenzoate in combination with $\left\{R_{n} S n\right\}$ ( $n=2$ and 3). Cryst. Growth Des., 2019, 19, 6656-6671, DOI: 10.1021/acs. cgd.9b01045.

Chandrasekhar V., Thirumoorthi R., Coordination polymers containing ferrocene backbone. Synthesis, structure and electrochemistry. Dalton Trans., 2010, 39, 2684-2691, DOI: 10.1039/b922044e.

Chandrasekhar V., Mohapatra C., Metre R.K., Reactions of 5-(pyridin4-yl-methyleneamino)isophthalic acid with triorganotin oxides and chloride. Formation of one-dimensional- and two-dimensional-coordination polymers. Cryst. Growth Des., 2013, 13, 4607-4614, DOI: 10.1021/cg401201w.

Chandrasekhar V., Nagendran S., Baskar V., Organotin assemblies containing Sn-O bonds. Coord. Chem. Rev., 2002, 235, 1-52. DOI: 10.1016/S0010-8545(02)00178-9.

Chen L., Wang Z., Qiu T., Sun R., Zhao Z., Tian L., et al., Synthesis, structural characterization and properties of triorganotin complexes of Schiff base derived from 3-aminobenzoic acid and salicylaldehyde or 2,4-pentanedione. Appl. Organomet. Chem., 2020, 34, e5790, DOI: 10.1002/aoc.5790.

Deacon G.B., Phillips R.J., Relationships between the carbon-oxygen stretching frequencies of carboxylato complexes and the type of carboxylate coordination. Coord. Chem. Rev., 1980, 33, 227-250. DOI: 10.1016/S0010-8545(00)80455-5.

Holecek J., Nadvornik M., Handlir K., ${ }^{13} \mathrm{C}$ and ${ }^{119} \mathrm{Sn}$ NMR spectra of dibutyltin(IV) compounds. J. Organomet. Chem., 1986, 315, 299-308. DOI: 10.1016/0022-328X(86)80450-8.

Holecek J., Nadvorník M., Handlir K., Lycka A., ${ }^{13} \mathrm{C}$ and ${ }^{119}$ Sn NMR Study of some four- and five-coordinate triphenyltin compounds. J. Organomet. Chem., 1983, 241, 177-184, DOI: 10.1016/ S0022-328X(00)98505-X.

Khan A., Parveen S., Khalid A., Shafi S., Recent advancements in the anticancer potentials of phenylorganotin(IV) complexes. Inorg. Chim. Acta, 2020, 505, 119464, DOI: 10.1016/j.ica.2020.119464.

Kondo M., Yoshitomi T., Seki K., Matsuzaka H., Kitagawa S., Threedimensional framework with channeling cavities for small molecules: $\left\{\left[\mathrm{M}_{2}\left(4,4^{\prime}-\mathrm{bpy}\right)_{3}\left(\mathrm{NO}_{3}\right)_{4}\right] \cdot \mathrm{xH}_{2} \mathrm{O}\right\}_{\mathrm{n}}(\mathrm{M}=\mathrm{Co}, \mathrm{Ni}, \mathrm{Zn})$.
Angew. Chem. Int. Ed., 1997, 36, 1725-1727, DOI: 10.1002/ anie.199717251.

Kundu S., Mohapatra C., Chandrasekhar V., Cyclophosphazeneorganostannoxane hybrid motifs in polymeric and molecular systems. RSC Adv., 2014, 4, 53662-53664, DOI: 10.1039/ c4ra09371b.

Liu J., Lin Y., Liu M., Wang S., Li Y., Liu X., et al., Synthesis, structural characterization and cytotoxic activity of triorganotin 5-(salicylideneamino)salicylates. Appl. Organomet. Chem., 2019, 33, e4715, DOI: 10.1002/aoc.4715.

Ma C., Zhang J., Zhang R., Syntheses, characterizations, and crystal structures of organotin(IV) chloride complexes with 4,4'-bipyridine. Heteroatom Chem., 2004, 15, 338-346, DOI: $10.1002 /$ hc. 20016.

Ma C., Zhang Q., Zhang R., Wang D., Self-assembly of dialkyltin moieties and mercaptobenzoic acid into macrocyclic complexes with hydrophobic "pseudo-cage" or doubl-cavity structures. Chem. Eur. J., 2006, 12, 420-428, DOI: 10.1002/ chem. 200500590.

Prabusankar G., Murugavel R., Hexameric organotincarboxylates with cyclic and drum structures. Organometallics, 2004, 23, 5644-5647, DOI: 10.1021/om049584u.

Sheldrick G.M., A short history of SHELX. Acta Crystallogr., 2008, A64, 112-122, DOI: 10.1107/S0108767307043930.

Sheldrick G.M., SHELXL-Integrated space-group and crystal-structure determination. Acta Crystallogr., 2015, A71, 3-8, DOI: 10.1107/ S2053273314026370.

Shi X., Wang H., Li Y., Yang J., Chen L., Hui G., et al., Spectroscopic study of $\mathrm{Co}(\mathrm{II}), \mathrm{Ni}(\mathrm{II}), \mathrm{Zn}$ (II) complexes with 4,4'-bipyridine. Chem. Res. Chin. Univ., 2010, 26, 1011-1015.

Tian L.-J., Chen L.-X., An W.-G., Liu X.-C., Diorganotin complexes of $\mathrm{N}$-[4-(diethylamino)salicylidene]-(L)-tryptophane: syntheses, structures and properties. Chin. J. Struct. Chem., 2019, 38, 1977-1985, DOI: 10.14102/j.cnki.0254-5861.2011-2378.

Tian L., Li F., Zheng X., Sun Y., Yan D., Tu L., Synthesis, characterization and in vitro cytotoxicity of diorganotin complexes of 3,5-dinitrosalicylic acid. Synth. React. Inorg. M., 2011, 41, 454458, DOI: $10.1080 / 15533174.2011 .568426$.

Tian L., Wang R., Zhang J., Zhong F., Qiu Y., Synthesis and structural characterization of dialkyltin complexes of $\mathrm{N}$-salicylideneL-valine. Main Group Met. Chem., 2020, 43, 138-146, DOI: 10.1515/mgmc-2020-0017.

Zhang S., Wang W., Liu Q., Zheng X., Tian L., Synthesis, crystal structure and antibacterial activity of tricyclohexyltin salicylates. Main Group Met. Chem., 2016, 39, 87-92, DOI: 10.1515/mgmc-2016-0014.

Zang S.Q., Su Y., Li Y.Z., Ni Z.P., Meng Q.J., Assemblies of a new flexible multicarboxylate ligand and $\mathrm{d}^{10}$ metal centers toward the construction of homochiral helical coordinationpolymers: structures, luminescence, and NLO-active properties. Inorg. Chem., 2006, 45, 174-180, DOI: 10.1021/ic051502m. 